\title{
Behavioral response to tactile stimuli relates to brain response to affective touch in 12-month-old infants
}

\author{
Helga O. Miguel ${ }^{1,2}$ (i) | Óscar F. Gonçalves ${ }^{2,3}$ | Adriana Sampaio ${ }^{2}$
}

${ }^{1}$ National Institute of Child Health and Human Development, National Institutes of Health, Bethesda, Maryland

${ }^{2}$ Neuropsychophysiology Lab, CiPsi, School of Psychology, University of Minho, Braga, Portugal

${ }^{3}$ Spaulding Neuromodulation Center, Spaulding Rehabilitation Hospital, Harvard Medical School, Charlestown, Massachusetts

\section{Correspondence}

Helga O. Miguel, Neuropsychophysiology Lab, CiPsi, School of Psychology, University of Minho, Campus de Gualtar, 4710-057 Braga, Portugal and Section of Analytical and Functional Biophotonics, National Institute of Child Health and Human Development, National Institute of Health, 49 Convent Drive, 5A75, Bethesda, MD 20892.

Email: helga.miguel@nih.gov

\section{Funding information}

This study was supported by the Portuguese Science Foundation through an individual doctoral grant to Helga Miguel (SFRH/ BD/86694/2012). The work was conducted at Psychology Research Center (UID/ PSI/01662/2013), University of Minho, and supported by the Portuguese Science Foundation and the Portuguese Ministry of Science, Technology and Higher Education through national funds (PSI/01662) and cofinanced by FEDER through COMPETE2020 under the PT2020 Partnership Agreement (POCI-01-0145-FEDER-007653).

\begin{abstract}
Affective touch activates a brain network responsible for processing social-emotional stimuli in infants, children, and adults, with a core node in the superior temporal sulcus (STS). STS is known to be a region highly susceptible to individual variability, including for tactile stimuli processing. However, little is known about how this region is recruited to process affective touch in infancy. The aim of this study was to examine brain activity to affective touch in the temporal region (STS) and understand if it relates to behavioral patterns of sensory-over responsivity (SOR) to touch. Twelve-month-old infants ( $n=24$ ) were given affective and discriminative stimuli to the forearm while they were watching a silent movie. Brain activation was recorded in the STS for measures of oxy-hemoglobin $\left(\mathrm{HbO}_{2}\right)$ and deoxy-hemoglobin $(\mathrm{Hbb})$ using functional near infra-red spectroscopy (fNIRS). Aversive responses to tactile stimuli were measured using the Infant-Toddler Sensory Profile. A significant hemodynamic response increase in $\mathrm{HbO}_{2}$ to affective touch was observed in the STS for infants with less aversive behavioral responses to tactile stimuli. The findings suggest that brain activity in the STS for affective touch might be related to individual differences in the affective reaction toward touch.
\end{abstract}

\section{KEYWORDS}

fNIRS, infancy, sensory over-responsivity, touch processing

\section{1 | INTRODUCTION}

Touch is the primary source of soothing and comfort offered by a mother to her newborn. Nurturing touch is present at very early stages of development (Jean, Stack, \& Fogel, 2009), and interventions like skin-to-skin contact (i.e., kangaroo care) suggest that touch is related to several markers of well-being like reduced mortality, increased weight/height gain, reduced rates of infection or hypothermia, and better developmental outcomes in term and preterm infants (Charpak \& Ruiz, 2016; Conde-Agudelo \& Diaz-Rossello, 2016; Feldman, Eidelman, Sirota, \& Weller, 2002; Feldman, Weller, Sirota, \& Eidelman, 2002). Animal research suggests that maternal physical care behavior (e.g., licking and grooming) are important for the development of the central nervous system, having a life-long impact on the offspring's social-emotional development (Harlow \& Suomi, 1970; Meaney \& Szyf, 2005; Weaver et al., 2004). Touch seems to serve not only an important role in the maturation of the brain throughout development, but it is critical for the foundation 
of social bonding and emotional communication (Hertenstein, Verkamp, Kerestes, \& Holmes, 2006).

A specific category of tactile fibers that respond to gentle, caress-like slow skin-stroking, C-tactile (CT) fibers, has been hypothesized to play an important role in socially relevant touch, including the touch present in affiliative behaviors, such as light stroking from the mother to her child, a hug between friends, or an intimate caress in a couple (McGlone, Vallbo, Olausson, Loken, \& Wessberg, 2007; McGlone, Wessberg, \& Olausson, 2014; Morrison, Loken, \& Olausson, 2010). These fibers are instrumental for encoding the valence of a stimulus (Loken, Wessberg, Morrison, McGlone, \& Olausson, 2009), but have a weak localization resolution (Olausson et al., 2002). In addition, CT afferents are tuned to temperature, and fire more when the tactile stimulus is at skin temperature. Interestingly, these fibers perceived pleasantness of a tactile stimuli (Ackerley et al., 2014).

At brain level, the stimulation of these fibers elicits activation of the social-brain network, including the posterior insula, posterior superior temporal sulcus (pSTS), medial prefrontal cortex, and dorsal anterior cingulate cortex (Bjornsdotter, Gordon, Pelphrey, Olausson, \& Kaiser, 2014; Gordon et al., 2013; Kaiser et al., 2015; Olausson et al., 2002; Voos, Pelphrey, \& Kaiser, 2013). There is evidence that this network is already in place at around 5 years of age (Bjornsdotter et al., 2014). However, less is known about the emergence of this network in infancy. Few studies have examined affective touch during the first year of life and, from what exists, there are controversial findings. Some studies suggest that the brain response to affective tactile stimuli emerges between 10 and 12 months of age (Kida \& Shinoara, 2013; Miguel, Gonçalves, Cruz, \& Sampaio, 2018; Miguel, Lisboa, Gonçalves, \& Sampaio, 2018), whereas others suggest that the affective touch system is functional at very early stages of postnatal life (Jönsson et al., 2018; Tuulari et al., 2017).

Jönsson et al. (2018) and Tuulari et al. (2017) found greater activation to CT targeted touch (slow skin stroking compared to fast skin stroking for Jonsson's study, Tullari's study did not have a control condition) in the insular cortex in 1- and 2-month-old infants, suggesting that the network responsible for detecting pleasantness from tactile stimuli is in place quite early in development. In addition, both studies found activation in the superior temporal region, but to a lesser extent, suggesting that the response to slow stroking might follow a developmental trajectory from deeper brain regions of the cortex, namely the insular cortex, to more superficial regions, as with the posterior temporal sulcus (STS). Others have found that the response of the STS to affective touch was present in 12-month-olds (Miguel, Gonçalves, et al., 2018), but not in 7-month-olds (Miguel, Lisboa, et al., 2018), suggesting that this network emerges between 7 and 12 months of age. Consistent with this finding, another study found that the velocity closest to CT-targeted touch resulted in a decrease of arousal, but faster and slower velocities did not seem to affect arousal levels in a sample of 9 month-old infants (Fairhurst, Loken, \& Grossmann, 2014). In sum, the literature suggests that CT afferents are a strong candidate for mediating interpersonal communication and social behavior starting in early stages of development.
Particularly, the sense of touch (affective touch) seems to be intrinsically related with social cognition and our ability to bond with others (Dunbar, 1998; Hertenstein et al., 2006). In populations that lack social and emotional reciprocity, namely autism spectrum disorders (Kaiser et al., 2015) and in healthy adults who present autistic traits (Bennett, Bolling, Anderson, Pelphrey, \& Kaiser, 2014; Voos et al., 2013), research has shown that the processing of CT fibers is different than healthy controls. Namely, children and adolescents with ASD show reduced activity in response to CT-targeted touch in brain regions including bilateral insula and insular operculum, right posterior STS, bilateral temporoparietal junction, right fusiform gyrus and bilateral ventrolateral prefrontal cortex (Kaiser et al., 2015). In healthy adults, response to slow touch in brain regions involved in social-emotional information processing including the orbito-frontal cortex or the right pSTS correlate negatively with autistic traits (Bennett et al., 2014; Voos et al., 2013).

Interestingly, in children and adults, the response to slow skin touch in the STS seems to be modulated by individual differences. Brain activity in STS has been found to correlate with age and gender (Gordon et al., 2013) and autistic traits (Bennett et al., 2014; Voos et al., 2013). The STS seems to be not only sensitive to pleasant tactile stimuli, but also to aversive tactile stimuli in both healthy individuals and clinical samples (Green et al., 2015). An increase of brain activation in this region to aversive tactile stimuli in individuals with autism spectrum disorder (ASD) is heightened by an over-responsivity to tactile stimuli (Green et al., 2015). It is long acknowledged that individuals with ASD present aversive reactions to sensory stimuli (BenSasson et al., 2009; Rogers \& Ozonoff, 2005), showing increased defensive responses and lower pleasantness ratings to tactile stimuli (Tomchek \& Dunn, 2007). These defensive responses to tactile stimuli (also referred to as sensory defensiveness or sensory over-responsivity [SOR]) have been documented in the population with ASD at a behavioral level, but, more recently, at a brain level as well. SOR to tactile stimuli is related to hyperactivity in brain regions involved in primary sensory processing (Green et al., 2015), but also affective-emotional regions such as the posterior cingulate cortex and the insula (Cascio et al., 2012). Moreover, activity in emotional processing regions, namely the insula, amygdala, and temporal regions, has been reported to be correlated with parent-reported SOR symptoms (Green et al., 2015) and social impairment (Cascio et al., 2012).

SOR lies under the clinical umbrella of sensory modulation disorder (Miller, Anzalone, Lane, Cermak, \& Osten, 2007). SOR is characterized by exaggerated, intense, and/or prolonged responses to certain sensory stimuli that same-age peers find innocuous (Dunn, 1997; Miller et al., 2007), reflecting an imbalance between noticing a novel or threatening stimuli (sensitization) and adapting to familiar stimuli (habituation; Dunn, 1997). It is estimated that the prevalence of SOR is around $2.5 \%$ to $6.5 \%$ in typically developing children (Goldsmith, Van Hulle, Arneson, Schreiber, \& Gernsbacher, 2006; Schoen, Miller, \& Green, 2008; Van Hulle, Lemery-Chalfant, \& Goldsmith, 2015), although it co-occurs in many neurodevelopmental disorders, including ASD (Kern et al., 2007; Leekam, Nieto, Libby, Wing, \& Gould, 2007), fragile $X$ syndrome (Baranek et al., 2002), or attention deficit 
hyperactivity disorder (Yochman, Parush, \& Ornoy, 2004). Very little is known about the etiology of SOR, but recent findings on a population-based sample of typically developing twins (Goldsmith et al., 2006; Schoen et al., 2008; Van Hulle et al., 2015) suggest that risk factors, such as gestational age, birthweight, and temperament, contribute to the stability of SOR tactile symptoms over time.

Given previous findings that the brain response to affective stimuli within the STS might be in place during the first year of life and the variability of the STS activations in response to affective touch (Bjornsdotter et al., 2014; Davidovic, Jonsson, Olausson, \& Bjornsdotter, 2016; Kaiser et al., 2015; Voos et al., 2013), we studied the processing of affective touch by the STS at 12 months of age and examined whether brain activation to affective touch would depend on distinct behavioral responses to tactile stimuli. As a measure of brain activity, we used functional near infra-red spectroscopy (fNIRS), a neuroimaging tool that measures concentration of oxygenated, deoxygenated, and total hemoglobin related to neural activity by measuring the absorption of infra-red light projected through the scalp (Gervain et al., 2011; Lloyd-Fox, Blasi, \& Elwell, 2010; Vanderwert $\&$ Nelson, 2014). fNIRS is an optimal tool to measure brain activity in infants, because of its diminished susceptibility to movement and better spatial resolution compared to an EEG. In comparison with $\mathrm{fMRI}, \mathrm{fNIRS}$ yields a higher temporal resolution, is silent, and does not require that the individual lie still (Lloyd-Fox et al., 2010), allowing the study of brain activity while individuals are exposed to stimuli of various natures or even interacting with the environment (Vanderwert $\&$ Nelson, 2014). For a measure of SOR, we used the Infant-Toddler Sensory Profile, a parent questionnaire that assesses how sensory processing in various domains affects the child's daily function, in children from birth to 36 months (Dunn, 2002). Our hypothesis for the current study was that infants with more frequent SOR behaviors (stronger negative reaction) to touch stimuli would present less brain activation in the STS in response to affective touch.

\section{2 | METHODS}

\section{1 | Participantss}

Participants were 24 12-month-old infants (mean age $394.33 \pm$ 27.8 days, range 372-512, 11 females). Twenty-one additional infants were tested but excluded due to fussiness $(n=4)$, not having the minimum number of trials to be included $(n=7)$, motion artifacts and/or noisy data $(n=7)$, experimental error $(n=2)$ or not having completed the Sensory Profile $(n=1)$. Our attrition rate was $47 \%$, similar to other NIRS studies conducted with infants (Lloyd-Fox, Szeplaki-Kollod, Yin, \& Csibra, 2015). The study protocol was approved by the local Ethics Committee, and the mothers provided informed consent prior to data collection.

\subsection{Stimuli}

Stimuli consisted of touching with a $7 \mathrm{~cm}$ wide watercolor brush and $2 \times 2 \mathrm{~cm}$ squared-shape piece of wood. These stimuli were chosen to represent the affective (brush) and discriminative (wood block) dimensions of touch (Bennett et al., 2014; Kida \& Shinohara, 2013). Affective stimuli included slow strokes $(8 \mathrm{~cm} / \mathrm{s})$ moving the watercolor brush on the bare forearm of the infant, in a proximaldistal direction. Stimuli were always delivered in the right forearm of the infant. Stimuli were delivered by hand by one trained experimenter, as previous findings have shown that skin stroking by hand or robot are highly comparable (Triscoli, Olausson, Sailer, Ignell, \& Croy, 2013); this velocity is known to target CT fibers (Loken et al., 2009). Discriminative stimuli consisted of applying pressure with the wood block in the dorsal forearm in a proximaldistal direction for the same period to elicit the stimulation of $A \beta$ fibers. These myelinated fibers conduct impulses from low-threshold mechanoreceptors present in the skin and joints. These fibers conduct high-speed impulses $(50 \mathrm{~m} / \mathrm{s}$ ) and are important for discriminative functions like handling objects or exploring surfaces (McGlone et al., 2007, 2014). To parallel the same distance of the brush, the wood block was applied three times a second (between 21 and 24 stimuli applied). The discriminative stimuli did not include any stroking movement, assuring that the fibers stimulated were the $A \beta$ fibers.

There were two blocks for each experimental condition (affective, discriminative), each block consisting of eight trials each (Bennett et al., 2014). One trial consisted of $10 \mathrm{~s}$ of stimulation followed by a period of $20 \mathrm{~s}$ of rest. Stimuli were pseudorandomized, so that there were no consecutive blocks of the same stimuli. The baseline stimuli (rest) consisted of a video of the Czech cartoon Krtek playing continuously with the audio turned off throughout the session (Fairhurst et al., 2014). Triggers/ events for affective and discriminative touch were created using the UCL-NTS optical imaging system. The schematic representation of the paradigm is displayed in Figure 1.

\section{3 | Measures}

\subsection{1 | NIRS recording}

Infants were tested using the UCL-fNIRS topography system using two continuous wavelengths of source light at 780 and $850 \mathrm{~nm}$, sampled every $100 \mathrm{~ms}(10 \mathrm{~Hz}$; for a detailed description of fNIRS methodology, see Lloyd-Fox et al., 2010). The system consisted of 18 channels: nine placed over the left somatosensory region and nine placed over the right temporal region. This array was used as part of a broader study (Miguel, Gonçalves, et al., 2018; Miguel, Lisboa, et al., 2018) that examined the brain mechanisms for processing affective and discriminative touch in infancy. Optodes were placed in the right temporal region (see Figure 2), because this area has shown to become activated following affective touch administered to the right arm (Bennett et al., 2014; Gordon et al., 2013; Voos et al., 2013); and the left primary somatosensory cortex, a well-established target region for processing discriminative touch to the contralateral hand (see Figure S1). The array accounted for the limited number of channels and distinct somatosensory pathways for affective and discriminative touch ( $A \beta$ and $C T$ fibers). Based on our hypothesis that 


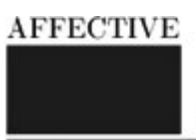

$10 \mathrm{~s}$

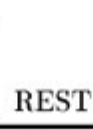

$20 s$
DISCRIMINATIVE

$(\times 8)$

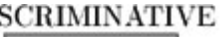

AFFECTIVE
DISCRIMINATIVE

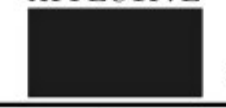

$10 \mathrm{~s}$
$10 \mathrm{~s}$

$20 \mathrm{~s}$

$20 \mathrm{~s}$

\section{$(\times 8)$}

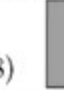

FIGURE 1 Experimental design. Each block consisted of a tactile stimulus delivered for $10 \mathrm{~s}$, followed by $20 \mathrm{~s}$ of rest. Each tactile stimulus was repeated 8 times per block. There was a total of 2 blocks per condition ( 2 affective +2 discriminative)
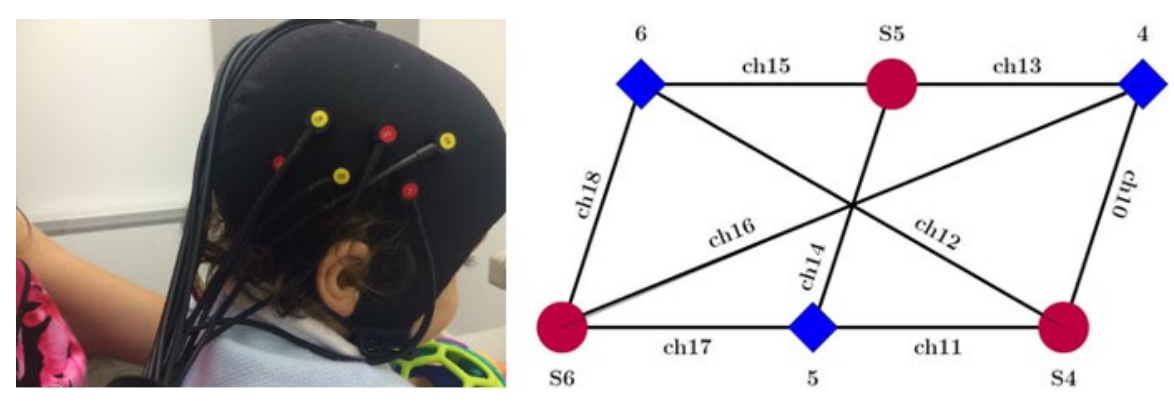

FIGURE 2 Display of the functional near infra-red spectroscopy probe in the temporal region. Hemodynamic activity was recorded from a total of nine channels. Red circles represent sources, and blue squares (schema of the array) and yellow circles (picture of the array) represent detectors. The near infra-red spectroscopy probe was customized to this experiment using an elastic cap (Easy Cap), with reference to the $10-5$ system

the pSTS is involved in processing CT-targeted touch, only the nine channels placed over this brain region were used for this study.

The NIRS probe was customized for this experiment using an elastic cap (Easy Cap), with reference to the 10-5 system (see Figure 2; Jurcak, Tsuzuki, \& Dan, 2007). The inter-optode distance was $22 \mathrm{~mm}$, except for the two longest channels that crossed the middle of the array (around $45 \mathrm{~mm}$ ). The probe was available in caps of different sizes ( 46 and $48 \mathrm{~cm}$ ) according to the head circumference of the infants; therefore, there was some variability in interoptode distance according to participants' head circumference. Measurements of head circumference $(M=46.41 \pm 1.24,43-49.5)$ and nasion-inion $(M=29.90 \pm 1.29,27.5-33)$ were taken to align the headgear with the 10-5 system before the experiment started. The cap was placed in the top of $\mathrm{Cz}$, with channel 11 (correspondent to TP8) placed above the preauricular point.

\subsection{2 | Infant/Toddler Sensory Profile}

The Infant-Toddler Sensory Profile is a parent questionnaire that assesses how sensory processing in various domains affects the child's daily function in children from birth to 36 months (Dunn, 2002). The tool consists of 48 judgment-based caregiver questions relative to sensory systems, including auditory, visual, tactile, vestibular, and oral, and sensory patterns, including seeking, avoiding, sensitivity, and registration. Each item is scored on a 5-point Likert Scale (1 = "Almost Never", 2 = "Occasionally", 3 = "Half of the time", 4 = "Frequently", 5 = "Almost Always"). Scores one standard deviation or more from the mean are expressed as More than Others or Less than Others, respectively. Scores two standard deviations or more from the mean are expressed as Much More Than Others or Much Less than Others, respectively. In this study, only the touch section of the Infant-Toddler Sensory Profile was examined (15 items). The mean raw scores on the Touch Section for the 12-month-old infants scored under Just Like the Majority of the others ( $M=47.48 \pm 7.75)$. To obtain a measure of aversive behaviors towards tactile stimuli/SOR/tactile defensiveness, we summed Avoiding and Sensitivity items from the Touch Section (10 items). This sum has been previously used since sensitivity and avoidance are highly correlated (Ben-Sasson et al., 2008; Miguel et al., 2017).

\section{4 | Procedure}

Sessions were scheduled according to the mother's availability and the infant's sleeping cycle, preferably after the infant took a nap and was fed and in quite an alert state. After the mother completed the consent form, the experimenter administered the demographic questionnaire. During this time, the infant played and became familiarized with the setting and with the experimenter. The infant sat in the mother's lap and a second experimenter played with the infant to direct his/her attention away, while head measurements were taken and the cap was being placed. The baby was then seated in a baby seat (Jellymom baby chair) to avoid physical contact with the mother, and the video was played immediately (Czech cartoon Krtek as in Fairhurst et al., 2014).

The mother and infant sat in front of a computer screen with the infant placed at approximately $70 \mathrm{~cm}$ from the screen. The experimenter sat to the right of the dyad, behind the infant and parent, administering the stimuli and redirecting the infant's attention to the screen throughout the experiment. The parents were instructed to avoid any kind of interaction with the infant and to only interfere when he/she became fussy. The experimenter also avoided interaction with the infant during the experiment. When needed, the experimenter introduced breaks to keep the infant involved in the session. The experiment finished when the infant completed all four blocks (16 $\mathrm{min}$ ) or when he/she became fussy/hard to sooth. All the 
sessions were videotaped for offline coding. The experiment took place in a dimly lit room to avoid light-interference.

\subsection{Data processing and analysis}

The video from each session was coded offline by an observer who was blind to the inclusion criteria. Participants were only included if they completed at least three valid trials (Lloyd-Fox, Wu, Richards, Elwell, \& Johnson, 2015). Trials were considered valid if: (1) the infant did not move the arm in any direction while the stimulus was being administered; (2) the infant was not looking at the experimenter or the mother while the stimulus was being administered; and (3) the infant did not touch the experimenter or the mother while the stimulus was being delivered. Participants completed an average of $6.68 \pm 2.15$ affective trials (range $4-13$ ) and $6.32 \pm 2.52$ (3-12) discriminative trials. No statistical difference was found for the number of trials completed $\left(\chi^{2}=31.39, p=0.885\right)$.

Changes in concentration of oxy-hemoglobin $\left(\mathrm{HbO}_{2}\right)$ or deoxyhemoglobin $(\mathrm{Hbb})$ measured in micromolar $(\mu \mathrm{m})$ were processed using HOMER2 (MGH-Martinos Center for Biomedical Imaging, Boston, MA), a MATLAB (The MathWorks, Inc., Natick, MA) software package. After behavioral coding, only valid trials were kept in Homer2 for data processing. The attenuated light intensities measured by the detecting optodes were converted to optical density units and assessed for movement artifact using Principal Component Analysis (PCA) set at 0.9. (Cooper et al., 2012). We chose to use PCA because we only included trials in which the infant was not moving the arm; it is preferable to reject trials rather than to correct them as other approaches do, as with wavelet motion correction. Data were low-pass filtered at 0.5 (Lloyd-Fox, Szeplaki-Kollod, et al., 2015) and used to calculate the change in concentration of the hemoglobin chromophores according to the modified Beer-Lambert Law (Delpy et al., 1988) assuming a pathlength factor of 5.13 (Duncan et al., 1995). Traces were segmented into 30-s epochs, starting two seconds prior to each stimulus. Baseline corresponded to the mean time from -2 to 0 , as in previous fNIRS studies (Ravicz, Perdue, Westerlund, Vanderwert, \& Nelson, 2015). This preliminary analysis allowed us to determine that the long channels (diagonal channels 12 and 16 in Figure 2) resulted in noisy data and, therefore, were excluded from further analysis.

A statistical analysis was performed using SAS (Statistical Analysis Software) $9.4 \mathrm{v}$. Both a significant increase in $\mathrm{HbO}_{2}$ or a decrease in $\mathrm{Hbb}$ are accepted as indicators of hemodynamic activity. For each channel, the maximum change in $\mathrm{HbO}_{2}$ (increase in chromophore concentration) and $\mathrm{Hbb}$ (decrease in chromophore concentration) in response to each experimental condition (affective and discriminative) was assessed relative to the baseline using a mixed-effect regression model. To include the maximum signal changes of both stimuli, fivetime windows were determined for the analyses: $t_{1}=0-5 \mathrm{~s} ; t_{2}=5-10 \mathrm{~s}$; $t_{3}=10-15 \mathrm{~s} ; t_{4}=15-20 \mathrm{~s}$ and $t_{5}=20-25 \mathrm{~s}$. The variable time was a dummy coded to capture non-linear relation over time. Following this initial analysis, a mixed model was computed for the channels that showed an increase in $\mathrm{HbO}_{2}$ hemodynamic activity and SOR as a factor. We used only this chromophore for this step of the analysis, as in previous NIRS studies (Lloyd-Fox et al., 2016). Since SOR was computed from the Touch Section, there are no normative values that determine whether an infant presents More Behaviors than Others or Less Behaviors than Others, as there are for the Touch Section (Dunn, 2002). Therefore, infants were divided into two groups using a median split: high SOR scores and low SOR scores. Reported $\mathrm{p}$ values were not adjusted for type-I error rates.

We first describe the results separately for affective and discriminative touch against the baseline. We then present the effect of SOR pattern in brain response for channels that presented an increase in $\mathrm{HbO}_{2}$.

\section{RESULTS}

\subsection{Effect of condition against baseline}

For affective touch, there was a significant hemodynamic increase of $\mathrm{HbO} 2$ for channel 10 at times two $(t(145)=5.13, p=0.025)$ and three $(t(145)=9.39, p=0.003)$, channel 11 at time one $(t(145)=5.26$, $p=0.023)$, channel 13 at times three $(t(145)=10.08, p=0.002)$ and four $(t(145)=4.69, p=0.032)$, channel 14 at time four $(t(145)=5.86$, $p=0.017)$, and channel 15 at time three $(t(145)=6.60, p=0.011)$ and $4(t(145)=5.51, p=0.020)$. In addition, marginally significant responses were also found for channel 11 at time two $(t(145)=3.62$, $p=0.060)$. A significant $\mathrm{Hbb}$ decrease was found for channel 13 at time four ( $t(145)=-2.99, p=0.003$ ) and channel 15 at time four ( $t$ $(145)=-2.01, p=0.05$; Figure 3). For discriminative touch, there was a significant hemodynamic increase in $\mathrm{HbO} 2$ over the pSTS region at time four for channel $17(t(145)=4.04, p=0.040)$. No significant changes were observed for $\mathrm{Hbb}$ concentration.

\subsection{Effect of SOR pattern in brain response to touch}

The mixed linear model for the hemodynamic activity with SOR as a factor revealed a significant interaction for affective touch in channel $10, F(1,120)=4.90, p=0.029$. Infants with less aversive behaviors toward tactile stimuli presented a higher hemodynamic response than children with more aversive behaviors $(M=0.032, S E=0.015$ and $M=-0.014, S E=0.015$, respectively). No interactions were found for channels $11, F(1,120)=1.35, p=0.274 ; 13, F(1,20)=2.03, p=0.156$; $14, F(1,120)=0.07, p=0.788$, or $15, F(1,120)=0.96, p=0.328$ (Figure 4). Additionally, no interaction was found for discriminative touch in channel $17, F(1,120)=0.09, p=0.768$.

\section{4 | DISCUSSION}

In this study, we investigated whether there is an association between brain response to affective touch in the STS region and infant's behavioral differences to tactile stimuli. Specifically, we used fNIRS to measure brain activity in the STS region to different types of tactile stimuli in a sample of infants of 12 months of age. Overall, our results confirm previous findings observed in adults (Bjornsdotter et 

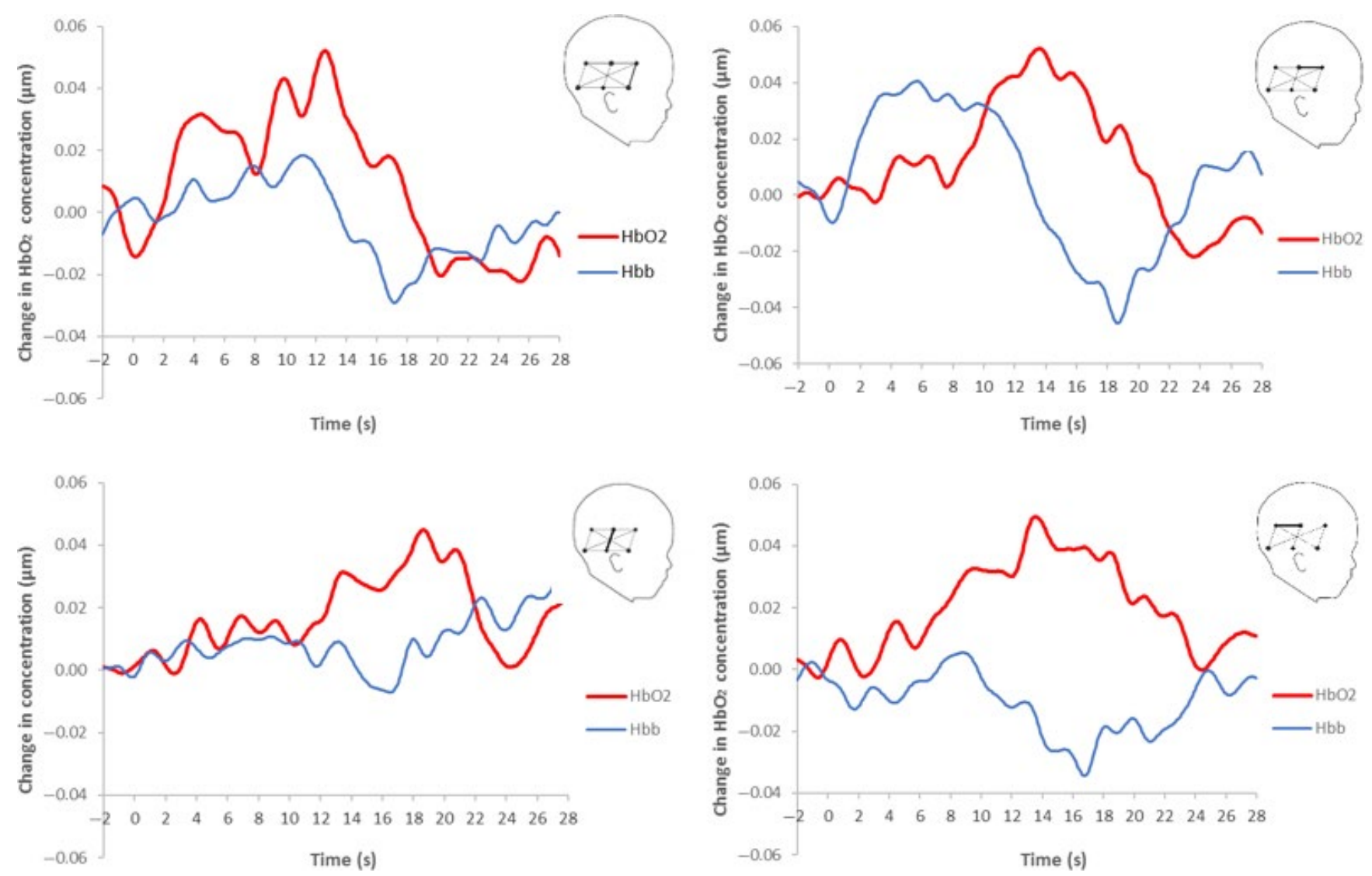

FIGURE 3 Hemodynamic response function for affective touch in channels 10 (top left), 13 (top right), 14 (bottom left) and 15 (bottom right)

al., 2014; Gordon et al., 2013; Kaiser et al., 2015; Voos et al., 2013), children (Kaiser et al., 2015), and infants (Miguel, Gonçalves, et al., 2018), showing that the STS is involved in processing CT-targeted touch in infancy. More importantly, we found that the emergence of brain activity to affective touch within the STS at 12 months of age was related to individual differences regarding affective processing of tactile stimuli. Infants with a lower SOR (i.e., less aversive reaction) at 12 months of age presented a higher hemodynamic response to affective touch. Previous studies found that the STS activation to affective touch is affected by individual variability, for example with age and gender (Bjornsdotter et al., 2014), perceived pleasantness (Davidovic et al., 2016), or autistic traits (Bennett et al., 2014; Voos et al., 2013). However, ours is the first study to report this effect in such early stages of development.

The right STS seems to be particularly susceptible to inter-individual variability, probably due to specific structural and functional characteristics of this region. In fact, at an anatomical level, asymmetries between hemispheres in the STS region can be seen as early as 26 weeks gestation, with the right STS being deeper than the left (Dubois et al., 2010; Glasel et al., 2011). This rightward bias of the right STS (one of the few regions that is asymmetric since birth) suggests an anatomical specificity, which may explain its involvement in several high-order functions, including language and theory of mind, as well as its abnormal function in some neurodevelopmental

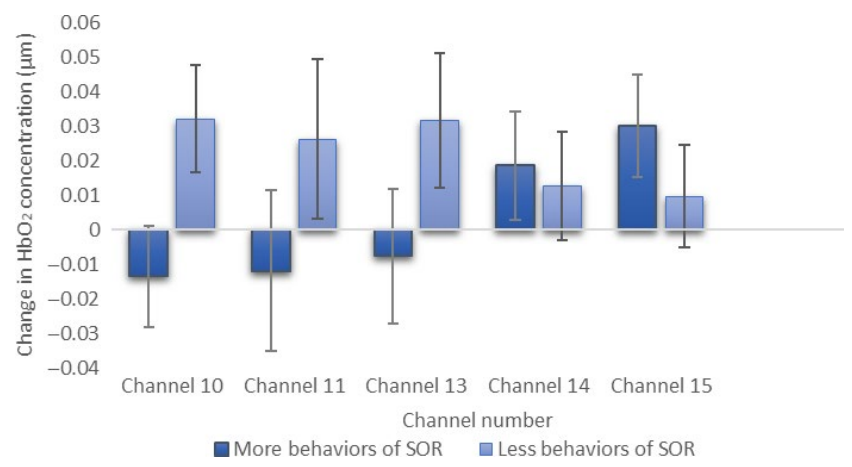

FIGURE 4 Hemodynamic response $\left(\mathrm{HbO}_{2}\right)$ to affective touch in channels placed over the temporal region in infants with more and less behaviors of sensory-over responsivity. ${ }^{*}$ Statistically significant difference with $p<0.05$

disorders (Glasel et al., 2011). At a functional level, it is known that regions sub-serving sensory-motor functions mature earlier in development, whereas associative high-order regions, including the temporal lobe, mature later (Lenroot \& Giedd, 2006). The temporal lobe undergoes an increasingly rapid maturation in the first years of life (Bonte et al., 2013; Tanaka, Matsui, Uematsu, Noguchi, \& Miyawaki, 2012), reaching a peak for gray-matter between the ages of 9 and 11 years. During this process, the STS region becomes 
gradually more specialized and focal (Bonte et al., 2013), suggesting an increased sensitivity to individual differences. Therefore, our finding of STS activity differences associated with distinct affective processing of tactile stimuli is not surprising.

SOR to tactile stimuli is known to be present in $2.5 \%$ to $6.5 \%$ of the general population (Goldsmith et al., 2006; Schoen et al., 2008). Overall, SOR symptoms (exaggerated, intense, and/or prolonged responses to certain sensory stimuli that same-age peers find innocuous) remain stable over the first years of life (Ben-Sasson, Carter, \& Briggs-Gowan, 2010), although there are inter-individual variations, with some children decreasing in symptoms and others experiencing latter onset (Van Hulle et al., 2015). For clinical populations, namely ASD, the trajectory is more consistent, with children presenting more stable symptoms across time, which are reported as one of the most challenging concerns by parents (Rogers \& Ozonoff, 2005). Moreover, retrospective studies show that infants avoidance behaviors to tactile stimuli are predictive of social impairments related with ASD in toddlerhood (Baranek, 1999; Mammen et al., 2015). Altogether, these findings suggest that sensory processing could be a valid tool when trying to understand more about ASD, since atypical sensory symptoms emerge before the onset of language, which is when the ASD diagnosis is currently made (APA, 2013).

The difficulty in standardizing cap placement because of head size and shape is a limitation inherent to fNIRS. Although we used 10-5 landmarks, and different cap sizes to fit the head circumference of the participant, future studies should incorporate digital localization to normalize channel placement in a standard space (Aasted et al., 2015). This would allow further inferences regarding the activity of each specific channel. The use of a questionnaire to measure SOR may introduce a subjectivity bias. Future studies should complement questionnaires with direct observation of infants' response to tactile stimuli. Measuring brain activity in infants using fNIRS is challenging and the attrition rate always results in a small number of infants included in the analysis. Future studies should rely on larger samples in order to potentiate variability in brain and behavioral measures. Additionally, it would be also interesting to include measures capturing mothers' behaviors and attitudes toward touch, as well as instances of touching interactions in mother-infant dyads (Brauer, Xiao, Poulain, Friederici, \& Schirmer, 2016). In conclusion, this study supports the affective-motivational dimension of CT afferents (McGlone et al., 2007, 2014; Morrison et al., 2010) and provides evidence that this system is not only present early in development, but might be also associated with distinct behavioral profiles of touch processing. This information can potentially be used in future study of infants at risk of neurodevelopmental disorders, namely ASD.

\section{ETHICAL STANDARDS}

The authors assert that all procedures contributing to this work comply with the ethical standards of the relevant national and institutional committees on human experimentation and with the Helsinki Declaration of 1975, as revised in 2008.

\section{CONFLICT OF INTEREST}

The authors declare they have no conflict of interest.

\section{DATA AVAILABILITY STATEMENT}

The data that support the findings of this study are available on request from the corresponding author. The data are not publicly available due to privacy or ethical restrictions.

\section{ORCID}

Helga O. Miguel iD https://orcid.org/0000-0002-0441-3158

\section{REFERENCES}

Aasted, C. M., Yucel, M. A., Cooper, R. J., Dubb, J., Tsuzuki, D., Becerra, L., $\&$ Boas, D. A. (2015). Anatomical guidance for functional near-infrared spectroscopy: AtlasViewer tutorial. Neurophotonics, 2, 020801. https://doi.org/10.1117/1.NPh.2.2.020801

Ackerley, R., Backlund Wasling, H., Liljencrantz, J., Olausson, H., Johnson, R. D., \& Wessberg, J. (2014). Human C-tactile afferents are tuned to the temperature of a skin-stroking caress. Journal of Neuroscience, 34(8), 2879-2883. https://doi.org/10.1523/JNEUR OSCl.2847-13.2014

APA. (2013). Diagnostic and statistical manual of mental disorders (5th ed.). Washington DC: Author.

Baranek, G. T. (1999). Autism during infancy: A retrospective video analysis of sensory-motor and social behaviors at 9-12 months of age. Journal of Autism and Developmental Disorders, 29, 213-224.

Baranek, G. T., Chin, Y. H., Hess, L. M., Yankee, J. G., Hatton, D. D., \& Hooper, S. R. (2002). Sensory processing correlates of occupational performance in children with fragile $X$ syndrome: Preliminary findings. American Journal of Occupational Therapy, 56, 538546.

Bennett, R. H., Bolling, D. Z., Anderson, L. C., Pelphrey, K. A., \& Kaiser, M. D. (2014). fNIRS detects temporal lobe response to affective touch. Social Cognitive and Affective Neuroscience, 9(4), 470-476. https://doi. org/10.1093/scan/nst008

Ben-Sasson, A., Carter, A. S., \& Briggs-Gowan, M. J. (2010). The development of sensory over-responsivity from infancy to elementary school. Journal of Abnormal Child Psychology, 38, 1193-1202. https:// doi.org/10.1007/s10802-010-9435-9

Ben-Sasson, A., Cermak, S. A., Orsmond, G. I., Tager-Flusberg, H., Kadlec, M. B., \& Carter, A. S. (2008). Sensory clusters of toddlers with autism spectrum disorders: Differences in affective symptoms. Journal of Child Psychology and Psychiatry, and Allied Disciplines, 49(8), 817-825. https://doi.org/10.1111/j.1469-7610.2008.01899.x.

Ben-Sasson, A., Hen, L., Fluss, R., Cermak, S. A., Engel-Yeger, B., \& Gal, E. (2009). A meta-analysis of sensory modulation symptoms in individuals with autism spectrum disorders. Journal of Autism and Developmental Disorders, 39, 1-11. https://doi.org/10.1007/ s10803-008-0593-3

Bjornsdotter, M., Gordon, I., Pelphrey, K. A., Olausson, H., \& Kaiser, M. D. (2014). Development of brain mechanisms for processing affective touch. Frontiers in Behavioural Neurosciences, 8, https://doi. org/10.3389/fnbeh.2014.00024

Bonte, M., Frost, M. A., Rutten, S., Ley, A., Formisano, E., \& Goebel, R. (2013). Development from childhood to adulthood increases morphological and functional inter-individual variability in the right superior temporal cortex. Neurolmage, 83, 739-750. https://doi. org/10.1016/j.neuroimage.2013.07.017 
Brauer, J., Xiao, Y., Poulain, T., Friederici, A. D., \& Schirmer, A. (2016). Frequency of maternal touch predicts resting activity and connectivity of the developing social brain. Cerebral Cortex, 26, 3544-3552. https://doi.org/10.1093/cercor/bhw137

Cascio, C. J., Moana-Filho, E. J., Guest, S., Nebel, M. B., Weisner, J., Baranek, G. T., \& Essick, G. K. (2012). Perceptual and neural response to affective tactile texture stimulation in adults with autism spectrum disorders. Autism Research, 5, 231-244. https://doi. org/10.1002/aur.1224

Charpak, N., \& Ruiz, J. G. (2016). The Kangaroo Mother Care Method: From scientific evidence generated in Colombia to worldwide practice. Journal of Clinical Epidemiology, https://doi.org/10.1016/j.jclin epi.2016.05.019

Conde-Agudelo, A., \& Diaz-Rossello, J. L. (2016). Kangaroo mother care to reduce morbidity and mortality in low birthweight infants. Cochrane Database of Systematic Reviews, 8, CD002771. https://doi. org/10.1002/14651858.CD002771.pub4

Cooper, R. J., Selb, J., Gagnon, L., Phillip, D., Schytz, H. W., Iversen, H. K., ... Boas, D. A. (2012). A systematic comparison of motion artifact correction techniques for functional near-infrared spectroscopy. Front Neurosci, 6, 147. https://doi.org/10.3389/fnins.2012.00147

Davidovic, M., Jonsson, E. H., Olausson, H., \& Bjornsdotter, M. (2016). Posterior superior temporal sulcus responses predict perceived pleasantness of skin stroking. Frontiers in Human Neuroscience, 10, 432. https://doi.org/10.3389/fnhum.2016.00432

Delpy, D. T., Cope, M., van der Zee, P., Arridge, S., Wray, S., \& Wyatt, J. (1988). Estimation of optical pathlength through tissue from direct time of flight measurement. Physics in Medicine \& Biology, 33(12), 1433-1442. https://doi.org/10.1088/0031-9155/33/12/008

Dubois, J., Benders, M., Lazeyras, F., Borradori-Tolsa, C., Leuchter, R. H., Mangin, J. F., \& Huppi, P. S. (2010). Structural asymmetries of perisylvian regions in the preterm newborn. Neurolmage, 52, 32-42. https:// doi.org/10.1016/j.neuroimage.2010.03.054

Dunbar, R. (Ed.). (1998). Grooming, gossip and the evolution of language Cambridge: Harvard University Press.

Duncan, A., Meek, J. H., Clemence, M., Elwell, C. E., Tyszczuk, L., Cope, M., \& Delpy, D. T. (1995). Optical pathlength measurements on adult head, calf and forearm and the head of the newborn infant using phase resolved optical spectroscopy. Physics in Medicine \& Biology, 40(2), 295-304. https://doi.org/10.1088/0031-9155/40/2/007

Dunn, W. (1997). The impact of sensory processing abilities on the daily lives of young children and their families: A conceptual model. Infants and Young Children, 9, 23-35. https://doi.org/10.1097/00001163 199704000-00005

Dunn, W. (2002). The infant/toddler sensory profile. San Antonio, TX: Psychological Corporation.

Fairhurst, M. T., Loken, L., \& Grossmann, T. (2014). Physiological and behavioral responses reveal 9-month-old infants' sensitivity to pleasant touch. Psychological Science, 25, 1124-1131. https://doi. org/10.1177/0956797614527114

Feldman, R., Eidelman, A. I., Sirota, L., \& Weller, A. (2002). Comparison of skin-to-skin (kangaroo) and traditional care: Parenting outcomes and preterm infant development. Pediatrics, 110(1 Pt 1), 16-26. https:// doi.org/10.1542/peds.110.1.16

Feldman, R., Weller, A., Sirota, L., \& Eidelman, A. I. (2002). Skin-to-Skin contact (Kangaroo care) promotes self-regulation in premature infants: Sleep-wake cyclicity, arousal modulation, and sustained exploration. Developmental Psychology, 38, 194-207. https://doi. org/10.1037/0012-1649.38.2.194

Gervain, J., Mehler, J., Werker, J., Nelson, C., Csibra, G., Lloyd-Fox, S., ... Aslin, R. (2011). Near-infrared spectroscopy: A report from the McDonnell infant methodology consortium. Developmental Cognitive Neuroscience, 1(1), 22-46. https://doi.org/10.1016/j. dcn.2010.07.004
Glasel, H., Leroy, F., Dubois, J., Hertz-Pannier, L., Mangin, J. F., \& Dehaene-Lambertz, G. (2011). A robust cerebral asymmetry in the infant brain: The rightward superior temporal sulcus. Neurolmage, 58 , 716-723. https://doi.org/10.1016/j.neuroimage.2011.06.016

Goldsmith, H. H., Van Hulle, C. A., Arneson, C. L., Schreiber, J. E., \& Gernsbacher, M. A. (2006). A population-based twin study of parentally reported tactile and auditory defensiveness in young children. [Twin Study]. Journal of Abnormal Child Psychology, 34(3), 393-407. https://doi.org/10.1007/s10802-006-9024-0

Gordon, I., Voos, A. C., Bennett, R. H., Bolling, D. Z., Pelphrey, K. A., \& Kaiser, M. D. (2013). Brain mechanisms for processing affective touch. Human Brain Mapping, 34(4), 914-922. https://doi. org/10.1002/hbm. 21480

Green, S. A., Hernandez, L., Tottenham, N., Krasileva, K., Bookheimer, S. Y., \& Dapretto, M. (2015). Neurobiology of sensory overresponsivity in youth with autism spectrum disorders. JAMA Psychiatry, 72(8), 778-786. https://doi.org/10.1001/jamapsychiatry.2015.0737

Harlow, H. F., \& Suomi, S. J. (1970). Nature of love-simplified. American Psychologist, 25(2), 161-168. https://doi.org/10.1037/h0029383

Hertenstein, M. J., Verkamp, J. M., Kerestes, A. M., \& Holmes, R. M. (2006). The communicative functions of touch in humans, nonhuman primates, and rats: A review and synthesis of the empirical research. Genetic, Social, and General Psychology Monographs, 132(1), 5-94. https://doi.org/10.3200/MONO.132.1.5-94

Jean, A. D., Stack, D. M., \& Fogel, A. (2009). A longitudinal investigation of maternal touching across the first 6 months of life: Age and context effects. Infant Behav Dev, 32, 344-349. https://doi.org/10.1016/j. infbeh.2009.04.005

Jönsson, E. H., Kotilahti, K., Heiskala, J., Wasling, H. B., Olausson, H., Croy, I., ... Nissilä, I. (2018). Affective and non-affective touch evoke differential brain responses in 2-month-old infants. Neurolmage, 169, 162-171. https://doi.org/10.1016/j.neuroimage.2017.12.024

Jurcak, V., Tsuzuki, D., \& Dan, I. (2007). 10/20, 10/10, and 10/5 systems revisited: Their validity as relative head-surface-based positioning systems. Neurolmage, 34, 1600-1611. https://doi.org/10.1016/j. neuroimage.2006.09.024

Kaiser, M. D., Yang, D.-J., Voos, A. C., Bennett, R. H., Gordon, I., Pretzsch, C., ... Pelphrey, K. A. (2015). Brain mechanisms for processing affective (and nonaffective) touch are atypical in autism. Cerebral Cortex, 26, 2705-2714. https://doi.org/10.1093/cercor/bhv125

Kern, J. K., Trivedi, M. H., Grannemann, B. D., Garver, C. R., Johnson, D. G., Andrews, A. A., ... Schroeder, J. L. (2007). Sensory correlations in autism. Autism, 11, 123-134. https://doi.org/10.1177/1362361307 075702

Kida, T., \& Shinohara, K. (2013). Gentle touch activates the anterior prefrontal cortex: An NIRS study. [Research Support, Non-U.S. Gov't]. Neuroscience Research, 76, 76-82. https://doi.org/10.1016/j. neures.2013.03.006

Leekam, S. R., Nieto, C., Libby, S. J., Wing, L., \& Gould, J. (2007). Describing the sensory abnormalities of children and adults with autism. [Research Support, Non-U.S. Gov't]. Journal of Autism and Developmental Disorders, 37, 894-910. https://doi.org/10.1007/ s10803-006-0218-7

Lenroot, R. K., \& Giedd, J. N. (2006). Brain development in children and adolescents: Insights from anatomical magnetic resonance imaging. [Review]. Neuroscience and Biobehavioral Reviews, 30, 718-729. https ://doi.org/10.1016/j.neubiorev.2006.06.001

Lloyd-Fox, S., Begus, K., Halliday, D., Pirazzoli, L., Blasi, A., Papademetriou, M., ... Elwell, C. E. (2016). Cortical specialisation to social stimuli from the first days to the second year of life: A rural Gambian cohort. Developmental Cognitive Neuroscience, https://doi.org/10.1016/j. dcn.2016.11.005

Lloyd-Fox, S., Blasi, A., \& Elwell, C. (2010). Illuminating the developing brain: The past, present and future of functional near infrared 
spectroscopy. Neuroscience \& Biobehavioral Reviews, 34(3), 269-284. https://doi.org/10.1016/j.neubiorev.2009.07.008

Lloyd-Fox, S., Szeplaki-Kollod, B., Yin, J., \& Csibra, G. (2015). Are you talking to me? Neural activations in 6-month-old infants in response to being addressed during natural interactions. Cortex, 70, https:// doi.org/10.1016/j.cortex.2015.02.005

Lloyd-Fox, S., Wu, R., Richards, J. E., Elwell, C. E., \& Johnson, M. H. (2015). Cortical activation to action perception is associated with action production abilities in young infants. Cerebral Cortex, 25, 289-297. https ://doi.org/10.1093/cercor/bht207

Loken, L. S., Wessberg, J., Morrison, I., McGlone, F., \& Olausson, H. (2009). Coding of pleasant touch by unmyelinated afferents in humans. Nature Neuroscience, 12, 547-548. https://doi.org/10.1038/nn.2312

Mammen, M. A., Moore, G. A., Scaramella, L. V., Reiss, D., Ganiban, J. M., Shaw, D. S., ... Neiderhiser, J. M. (2015). Infant avoidance during a tactile task predicts autism spectrum behaviors in toddlerhood. Infant Mental Health Journal, 36, 575-587. https://doi.org/10.1002/ imhj.21539

McGlone, F., Vallbo, A. B., Olausson, H., Loken, L., \& Wessberg, J. (2007). Discriminative touch and emotional touch. Canadian Journal of Experimental Psychology, 61, 173-183. https://doi.org/10.1037/cjep2 007019

McGlone, F., Wessberg, J., \& Olausson, H. (2014). Discriminative and affective touch: Sensing and feeling. Neuron, 82, 737-755. https://doi. org/10.1016/j.neuron.2014.05.001

Meaney, M. J., \& Szyf, M. (2005). Maternal care as a model for experiencedependent chromatin plasticity? [Review]. Trends in Neurosciences, 28, 456-463. https://doi.org/10.1016/j.tins.2005.07.006

Miguel, H., Gonçalves, Ó., Cruz, S., \& Sampaio, A. (2018). Infant brain response to affective and discriminative touch: A longitudinal study using fNIRS. Social Neuroscience, 1-12. https://doi. org/10.1080/17470919.2018.1536000

Miguel, H., Lisboa, I., Gonçalves, Ó., \& Sampaio, A. (2018). Brain mechanisms for processing discriminative and affective touch in 7-monthold infants. Developmental Cognitive Neuroscience, 35, 20-27. https:// doi.org/10.1016/j.den.2017.10.008

Miguel, H., Sampaio, A., Martínez-Regueiro, R., Gómez-Guerrero, L., López-Dóriga, C., Gómez, S., ... Fernández-Prieto, M. (2017). Touch processing and social behavior in ASD. Journal of Autism and Developmental Disorders, 47(8), 2425-2433. https://doi.org/10.1007/ s10803-017-3163-8

Miller, L. J., Anzalone, M. E., Lane, S. J., Cermak, S. A., \& Osten, E. T. (2007). Concept evolution in sensory integration: A proposed nosology for diagnosis. [Editorial]. American Journal of Occupational Therapy, 61, 135-140. https://doi.org/10.5014/ajot.61.2.135

Morrison, I., Loken, L. S., \& Olausson, H. (2010). The skin as a social organ. [Review]. Experimental Brain Research, 204, 305-314. https:// doi.org/10.1007/s00221-009-2007-y

Olausson, H., Lamarre, Y., Backlund, H., Morin, C., Wallin, B. G., Starck, G., ... Bushnell, M. C. (2002). Unmyelinated tactile afferents signal touch and project to insular cortex. Nature Neuroscience, 5, 900-904. https://doi.org/10.1038/nn896

Ravicz, M. M., Perdue, K. L., Westerlund, A., Vanderwert, R. E., \& Nelson, C. A. (2015). Infants' neural responses to facial emotion in the prefrontal cortex are correlated with temperament: A functional nearinfrared spectroscopy study. Frontiers in Psychology, 6, 922. https:// doi.org/10.3389/fpsyg.2015.00922

Rogers, S. J., \& Ozonoff, S. (2005). Annotation: What do we know about sensory dysfunction in autism? A critical review of the empirical evidence. Journal of Child Psychology and Psychiatry, 46, 1255-1268. https://doi.org/10.1111/j.1469-7610.2005.01431.x

Schoen, S. A., Miller, L. J., \& Green, K. E. (2008). Pilot study of the Sensory Over-Responsivity Scales: Assessment and inventory. American Journal of Occupational Therapy, 62, 393-406. https://doi. org/10.5014/ajot.62.4.393

Tanaka, C., Matsui, M., Uematsu, A., Noguchi, K., \& Miyawaki, T. (2012). Developmental trajectories of the fronto-temporal lobes from infancy to early adulthood in healthy individuals. Developmental Neuroscience, 34, 477-487. https://doi.org/10.1159/000345152

Tomchek, S. D., \& Dunn, W. (2007). Sensory processing in children with and without autism: A comparative study using the short sensory profile. American Journal of Occupational Therapy, 61, 190-200. https ://doi.org/10.5014/ajot.61.2.190

Triscoli, C., Olausson, H., Sailer, U., Ignell, H., \& Croy, I. (2013). CToptimized skin stroking delivered by hand or robot is comparable. Frontiers in Behavioural Neurosciences, 7, 208. https://doi. org/10.3389/fnbeh.2013.00208

Tuulari, J., Scheinin, N., Lehtola, S., Merisaari, H., Saunavaara, J., Parkkola, R., ... Björnsdotter, M. (2017). Neural correlates of gentle skin stroking in early infancy. Developmental Cognitive Neuroscience, 35, 36-41. https://doi.org/10.1016/j.dcn.2017.10.004

Van Hulle, C., Lemery-Chalfant, K., \& Goldsmith, H. H. (2015). Trajectories of sensory over-responsivity from early to middle childhood: Birth and temperament risk factors. PLoS ONE, 10(6), e0129968. https:// doi.org/10.1371/journal.pone.0129968

Vanderwert, R., \& Nelson, C. (2014). The use of near-infrared spectroscopy in the study of typical and atypical development. Neurolmage, 85, 264-271. https://doi.org/10.1016/j.neuroimage.2013.10. 009

Voos, A. C., Pelphrey, K. A., \& Kaiser, M. D. (2013). Autistic traits are associated with diminished neural response to affective touch. Social Cognitive and Affective Neuroscience, 8, 378-386. https://doi. org/10.1093/scan/nss009

Weaver, I. C. G., Cervoni, N., Champagne, F. A., D'Alessio, A. C., Sharma, S., Seckl, J. R., ... Meaney, M. J. (2004). Epigenetic programming by maternal behavior. Nature Neuroscience, 7, 847-854. https://doi. org $/ 10.1038 / \mathrm{nn} 1276$

Yochman, A., Parush, S., \& Ornoy, A. (2004). Responses of preschool children with and without ADHD to sensory events in daily life. American Journal of Occupational Therapy, 58, 294-302. https://doi. org/10.5014/ajot.58.3.294

\section{SUPPORTING INFORMATION}

Additional supporting information may be found online in the Supporting Information section at the end of the article.

How to cite this article: Miguel HO, Gonçalves ÓF, Sampaio

A. Behavioral response to tactile stimuli relates to brain response to affective touch in 12-month-old infants. Developmental Psychobiology. 2019;00:1-9. https://doi. org/10.1002/dev.21891 